\title{
Mutation analysis in the MECP2 gene and genetic counselling for Rett syndrome
}

\author{
H Gill, J P Cheadle, J Maynard, N Fleming, S Whatley, T Cranston, E M Thompson, \\ H Leonard, M Davis, J Christodoulou, O Skjeldal, F Hanefeld, A Kerr, A Tandy, \\ D Ravine, A Clarke
}

J Med Genet 2003;40:380-384

W looked for pathogenic MECP2 mutations in 11 amilies with an index case affected by Rett syndrome (RTT), together with a sib or other relative affected by RTT or a less specific developmental disturbance. In one family, we detected the same MECP2 mutation in two affected sisters and their unaffected mother, who was subsequently shown to have skewed X chromosome inactivation. In five families, one affected subject was found to have a MECP2 mutation, but the other relative in whom a diagnosis of RTT was suspected, did not carry this or any other detectable $M E C P 2$ mutation. In the remaining five families, no MECP2 mutation was detected in any subject. These results suggest that familial RTT is rare and may be overdiagnosed. Furthermore, and despite the small probability of recurrence, many relatives of females with the usual, sporadic RTT may seek genetic testing to clarify their situation.

Rett syndrome (RTT) is a neurodevelopmental disorder that mostly affects females and is usually sporadic. It has therefore often been considered to be an X linked dominant condition with male lethality, although it is now recognised that de novo mutations in RTT occur predominantly on the paternally derived $X$ chromosome and this could lead to similar observations. ${ }^{1-4}$ It is an important cause of profound mental handicap in girls, accounting for up to $10 \%$ of all cases. The diagnosis is currently based upon the clinical criteria proposed by the Rett Syndrome Working Group in 1988. ${ }^{5}$ The major criteria are: (1) normal pre- and perinatal period and apparently normal development for the first 6 months of life, (2) a period of regression occurring at 6 months to 3 years of age, (3) deceleration in head growth, (4) acquisition of stereotypical hand movements, and (5) eventual profound developmental delay. In addition, there are a number of supportive criteria that can help in making the diagnosis, including irregularities of ventilation, epilepsy, scoliosis, growth retardation, and short fourth metatarsal bones. ${ }^{67}$

A number of less typical RTT phenotypes have been described. ${ }^{8}$ Early onset without any normal development has been described as a "congenital variant" form" and cases with persisting speech as a "preserved speech variant". ${ }^{10}{ }^{11}$ A variety of phenotypes have been described in males associated with MECP2 mutations, including severe encephalopathy sometimes accompanied by polymicrogyria. ${ }^{12}$ Where a possible case of RTT already exists in a family, atypical RTT is often considered in the differential diagnosis of a relative with disabilities. This raises important questions for the genetic counselling provided for such families.

The methyl CpG binding protein 2 gene, $M E C P 2$, encodes a global transcriptional silencer and was recently identified as the gene defective in RTT. ${ }^{13}$ Mutations in MECP2 so far identified in association with RTT are thought to cause loss of function of the protein and therefore a generalised derepression of transcription. Many groups have undertaken mutation analysis, using a variety of molecular techniques, in both classically and non-classically affected females. Mutation detection in

\section{Key points}

- We report 11 families with two females thought to be affected by Rett syndrome (RTT).

- In one family, there were MECP2 mutations in the two affected sisters and their healthy mother. In five families, a MECP2 mutation was found in one affected female but not in the other, possibly affected female. In five families, no MECP2 mutation was found.

- We conclude (1) that RTT is only rarely familial, (2) that if girls with RTT who have MECP2 mutations have sisters with developmental difficulties, then this is more likely to have a separate cause. In addition, (3) sisters, mothers, and aunts of girls with RTT are likely to seek MECP2 genetic testing when this is available.

classically affected females varies from $46 \%$ to $80 \% \cdot{ }^{14-22}$ MECP2 mutations therefore account for the majority of mutations in classically affected females and this suggests that another major RTT locus is unlikely. In atypical cases of RTT, the rate of mutation detection is lower, suggesting that other aetiologies are responsible for at least some of the cases. ${ }^{14}$

Approximately $1 \%$ of all RTT cases are thought to be familial and clinically unaffected carrier mothers have been reported, some with either extreme skewing of $\mathrm{X}$ inactivation or presumed gonadal mosaicism ${ }^{15}$ 16-25 $^{23}$ (personal communications, S Budden 19.10.2000, S Whatley 13.11.2001, Raffaele et al, submitted for publication). It is now possible to investigate further those families in whom RTT was thought to be familial by molecular genetic analysis of MECP2. We studied 10 families in which two subjects had classical or atypical RTT, to determine the role of mutations in the coding region of $M E C P 2$ in apparently familial RTT.

\section{MATERIAL AND METHODS}

DNA samples were collected from 21 affected subjects belonging to 11 families in which two members had clinical features strongly suggestive of classical or atypical RTT. Samples were also collected from the unaffected sister in one family and from the mothers of affected subjects when appropriate. Mutation analysis in members of families 1, 2, 3, and 4 has been reported previously. ${ }^{14}$ Where linkage studies have also been reported, we refer to these in the text.

Clinical details were collected by clinical examination, from the case notes, and from the clinicians involved with each patient. Specific information was collected regarding the major diagnostic criteria, to establish the presence or absence of (1) a period of normality, (2) a period of regression, (3) deceleration in head growth, (4) stereotypical hand movements, and (5) profound developmental delay. Unless 


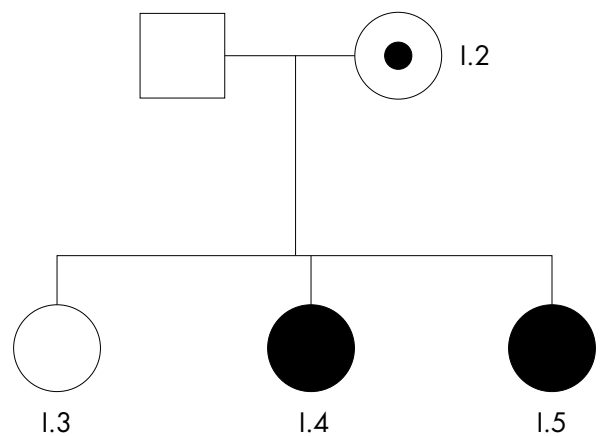

Figure 1 Pedigree of family 1.

otherwise stated, all relevant metabolic and neurological investigations have been undertaken to exclude an alternative diagnosis. For this study, females that met four out of five of the major criteria and at least two out of six of the supportive criteria were considered to have definite RTT, as well as those females who met all five of the major criteria.

In order to perform mutation analysis, the complete coding region (exons 2, 3, and 4), the flanking intronic splice site sequences, and the 5'UTR within exon 2 of MECP2 were amplified as three non-overlapping fragments, as previously described. ${ }^{14}$ Manual PCR product sequencing for exons 2 and 3 using the ThermoSequenase cycle sequencing kit (Amersham) and automated PCR product sequencing for exon 4 using the ThermoSequenase fluorescence cycle sequencing kit (Amersham) was carried out as previously described.$^{14}$ Every patient was sequenced for all three fragments and mutations were confirmed on both strands.

$\mathrm{X}$ inactivation status was assessed by PCR amplification of the androgen receptor (AR) locus, incorporating the trinucleotide polymorphic repeat in exon 1 and the $5^{\prime}$ methylation sites. This method was originally described by Allen et al, who reported the polymorphic repeat to have a heterozygosity of $90 \%$. The original method has been modified to use fluorescent technology. The primers used were as stated in the original paper, but the forward primer was labelled with the fluorescent dye ABI-FAM, and PCR controls were included with each batch of test samples (blank/no DNA, random controls, and controls with skewed X inactivation). For each sample two $10 \mu \mathrm{l}$ reactions were prepared. In reaction $1,500 \mathrm{ng}$ DNA were incubated at $37^{\circ} \mathrm{C}$ overnight with $1 \mu \mathrm{l}$ restriction enzyme buffer, $0.5 \mu \mathrm{l}$ (10 U) HpaII, $0.5 \mu \mathrm{l}$ ( $10 \mathrm{U}$ ) HhaI (all Kramel Biotech) and $\mathrm{dH}_{2} \mathrm{O}$. Reaction 2 serves as an undigested control allowing zygosity to be determined; 500 ng DNA was diluted with $\mathrm{dH}_{2} \mathrm{O}$ and $2.5 \mu \mathrm{l}$ of DNA from each reaction tube was independently amplified using standard PCR conditions ( $25 \mu \mathrm{l}$ reaction volume, $1.5 \mathrm{mmol} / \mathrm{l} \mathrm{MgCl}_{2}$ ). Cycle conditions were as in Allen et al, ${ }^{26}$ except 25 cycles. Denatured PCR products were electrophoresed and separated on a $4.2 \%, 12 \mathrm{~cm}$ long, $0.2 \mathrm{~mm}$ thick, polyacrylamide gel. This was run for $\sim 2$ hours on an ABI DNA Sequencer (PE-ABI, UK), using a GS500 internal size standard (manufacturer's instructions). Analysis uses ABI Genescan and Genotyper software packages (manufacturer's instructions). Signal output was assessed by eye. Two signals in an undigested track represent heterozygosity for the AR polymorphic repeat. If the corresponding digested track also had two signals of similar intensity, then the female was reported as having random $X$ inactivation, if there was only one signal (or the second was negligible) then the female was reported to have skewed $\mathrm{X}$ inactivation.

\section{RESULTS}

Family 1 (fig 1)

I.4 fulfils the diagnostic criteria for classical RTT. At the age of 17 years she was able to walk alone, grasp objects for a brief period of time, and understand one or two words. She was found to carry the R133C missense mutation. $\mathrm{X}$ inactivation studies on peripheral blood leucocytes showed a random pattern of X inactivation. Her younger sister, I.5, also fulfilled the criteria for classical RTT. At the age of 15 years she could walk alone and feed with a spoon. She had no speech but could understand simple commands. She also carried the R133C mutation and showed random $\mathrm{X}$ inactivation. The girls' mother, I.2, did not have RTT. She completed her education to the age of 21 years and worked as a teacher. She was found to have the R133C mutation in her peripheral blood leucocytes. X inactivation studies show that she has skewing of X chromosome inactivation with apparently complete inactivation of the mutation bearing $\mathrm{X}$ chromosome in her leucocytes.

This family has been reported previously and it is important to note that I.2 and I.4 have disordered urea cycle metabolism and that I.4, and to a lesser degree I.5, show evidence of abnormal metabolism of carbohydrates with fasting hypoglycaemia and hyperlactataemia. ${ }^{27}$ I.3, the unaffected sister of the two affected girls, recently requested testing for carrier status. The mutation was not detectable in her peripheral blood leucocytes. The origin of the mutation in this family appears to be on the maternal grandfather's $X$ chromosome, with the haplotype for markers DXS548, DXS1193, and DXS15 in Xq28 being inherited through the mother by both affected girls (family 8 in Xiang et $a l^{28}$ ).

\section{Family 2}

II.l, the older of two sisters with developmental problems, fulfilled the diagnostic criteria for classical RTT. A missense mutation, S134C, was identified in peripheral blood leucocytes. The younger sister, II.2, did not fulfil the criteria for classical RTT. Between 7 to 11 months there was some concern that her development was slowing. She lost social interest and verbalised much less than previously. Following this she made good developmental progress and by 4 years attended a mainstream school. She did not have a detectable mutation in the $M E C P 2$ coding region.

\section{Family 3}

III.1 and III.2 are a maternal aunt and niece. The niece, III.2, meets the criteria for classical RTT. She has been shown to have a truncating mutation, R294X, of the MECP2 gene. The maternal aunt, III.l, was described as having a history of regression but has moderate developmental delay. She sat at 6 months, had a number of words at 13 months, and walked at 18 months. At 27 months she became withdrawn but maintained her hand function. She maintained a higher level of hand function and language skills than would be expected in RTT. She had demonstrable deceleration in head growth and also had developed generalised seizures and stereotypical hand movements. She does not have a mutation in the MECP2 coding region detectable by comprehensive sequence analysis. Linkage analyses were performed with microsatellite markers on Xq28 but were not contributory. ${ }^{29}$

\section{Family 4 (fig 2)}

IV.2 has a clinical diagnosis of classical RTT. ${ }^{30}$ The P225R mutation in the MECP2 gene was identified in peripheral blood leucocytes. Her second cousin once removed and related through a male relative, IV.3, fulfilled the diagnostic criteria for classical RTT. While she was hypotonic in the neonatal period, her development appeared otherwise normal until 4 months of age when progress ceased. Slow developmental progress was re-established from 18 months onwards. Scoliosis was noted at 12 months and seizures began at 3 years, from which time she lost some skills including hand use, mobility, and communication skills. At the age of 6 years she was able to walk with an unsteady gait and also to finger feed. She has occasional hand wringing when concentrating. She does not have a mutation in the coding region of the MECP2 gene. 


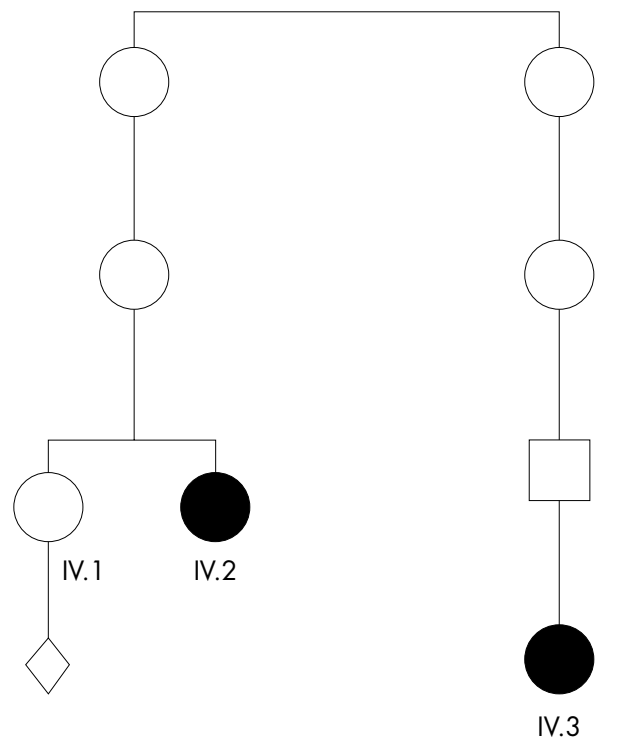

Figure 2 Pedigree of family 4.

IV.1, the healthy sister of IV.2, presented to her local genetics department in her first pregnancy requesting prenatal diagnosis. Mutation analysis of her leucocyte DNA and that of her parents was undertaken for the P225R mutation. Neither IV.I nor her mother carried the mutation in their peripheral blood leucocytes. IV.1 did not proceed with prenatal diagnosis and subsequently delivered a healthy boy.

\section{Family 5}

V.l, the eldest of two sisters with developmental difficulties, fulfilled the diagnostic criteria for RTT, although she has a higher level of skills than is usual. She was born following a normal pregnancy. Slow development became apparent by 10 months of age, when she began to scream for long periods of time. At 6 years she developed generalised seizures and scoliosis and she remains profoundly disabled.

The younger sister, V.2, was born following a normal pregnancy. There was no period of regression but slow developmental progress was apparent by 11 months. By 3 years she was able to walk with callipers and by 6 years was able to finger feed but had no speech. She wrings her hands in the midline and frequently places them in her mouth. She displayed bruxism and had short episodes of absences. A clinical diagnosis of atypical RTT was thought likely. These girls share all informative markers from a panel of Xq28 microsatellites (family 6 in Webb et al $^{29}$ but no mutation was detected in the $M E C P 2$ coding region in either child.

\section{Family 6}

VI.1, the elder of two sisters, fulfils the criteria for classical RTT. At the age of 33 years, she was able to walk with support. She had no appropriate speech and little understanding. She had occasional stereotypical hand movements and only limited hand use. The younger sister, VI.2, also fulfilled the criteria for classical RTT. At the age of 26 years she was unable to walk and had severe truncal ataxia, absent speech, and a mild scoliosis. Both sisters share the same maternal allele for DXS15 and for some other microsatellite markers in distal Xq28 (family 6 in Xiang et al, ${ }^{28}$ family 3 in Webb et $a l^{29}$ ) although neither had a detectable mutation in the coding region of the $M E C P 2$ gene.

\section{Family 7}

VII.1, the older of two sisters with severe developmental problems, had apparently normal development in the first year of life. At 2 years of age she was noted to have severe expressive speech delay and her developmental progress ceased. There was no evidence of regression. Although she no longer used her hands in play she was able to use a spoon and cup. There was no clear evidence of deceleration in head growth. At the age of 19 years she was able to walk but with a very crouched gait and she was still able to use a spoon and cup. VII.2, her younger sister, had no clear regression period and no documented deceleration in head growth. She had developed occasional hand stereotypical movements, but maintains relatively good hand use.

Both sisters have non-specific, dysmorphic facial features and, although they show some features of RTT, neither was considered to fulfil the diagnostic criteria for RTT. The sisters share their maternal Xq28 haplotype from DXS994 (in Xq27) to DXYS154 (Xqter), shown to be of grandmaternal origin (family 5 in Webb et $a^{29}$ ), but neither sister has a detectable mutation in the $M E C P 2$ coding region.

\section{Family 8}

VIII. 1 is the older of two sisters with developmental problems. She does not fulfil the diagnostic criteria for classical RTT but is thought to have a congenital form of the condition. ${ }^{8}{ }^{10}$ She appeared well until about 4 weeks when she developed feeding difficulties and hypertonia. Over the next few months her head growth decelerated. From 2 years she developed stereotypical hand movements, respiratory irregularities, teeth grinding, and epilepsy.

VIII.2 is also thought to have the congenital variant form of the condition. Her developmental profile has been almost identical to that of her sister, in that developmental delay was noted from the first few weeks of life. By the age of 5 years she displayed stereotypical hand movements, profound developmental delay, and respiratory dysfunction. These girls have opposite Xq28 haplotypes across the MECP2 gene region (family 4 in Webb et $\mathrm{l}^{29}$ ) and neither sister has a detectable mutation in the $M E C P 2$ coding region.

\section{Family 9}

IX.1 is the elder of two maternal half sisters with developmental problems and fulfils our criteria for "definite" RTT although not the full criteria for "classical" RTT. She has developed no speech, has intermittent episodes of breath holding and hyperventilation, and aerophagy. An MRI of her brain at 20 months was normal but a CT scan showed calcification, which was thought to be consistent with an intrauterine infection. This has not been confirmed serologically. Her younger half sister, IX.2, had developmental delay first suspected at 9 months and, at the age of 5 years, there was a plateau in her development and some loss of skills. She developed occasional hand wringing in the midline, episodes of hyperventilation, and a scoliosis. Neither of the half sisters has a detectable mutation in the MECP2 coding region.

\section{Family 10}

X.1 has developmental problems that fulfil the diagnostic criteria for classical RTT. Her sister X.2 had a clinical course consistent with RTT including breathing abnormalities, seizures, teeth grinding, and cold blue feet. Refractory seizures and pneumonia led to her death in 1979 at the age of 8 years, so that the diagnosis of RTT was never considered during her lifetime. Reference was made to this family before the availability of mutation testing. ${ }^{31}{ }^{32}$ Interestingly, the mother has bilateral short fourth metacarpals while X.1 also had a short right metacarpal and a short left metatarsal. Mutation testing has now been completed and has included both parents and her brother but DNA was not available from the dead sister X.2. Only the living affected patient X.1 has a $M E C P 2$ mutation, 806delG. She also has the c. $1459+10 \mathrm{C} \rightarrow \mathrm{T}$ change, a polymorphism shared with her mother and healthy brother. 


\section{Family 11}

XI.2, the younger of two sisters with developmental problems, fulfilled the diagnostic criteria for classical RTT. A truncating mutation (c.502C $>\mathrm{T}, \mathrm{R} 168 \mathrm{X}$ ) was identified in peripheral blood leucocytes. XI.1, the older sister, did not fulfil the criteria for classical RTT. Infantile spasms started in the first year of life associated with loss of neurodevelopmental skills. The seizure pattern was consistent with Lennox-Gastaut syndrome and severe refractory seizures, including debilitating atonic seizures, persisted. At 13 years of age, she is ambulant but with severe learning difficulties. Speech is restricted to sounds only, although she is able to communicate with Makaton signing. An MRI scan at 10 years of age showed a focus of heterotopic grey matter near the left lateral ventricle, associated with an overlying cortical anomaly resembling polymicrogyria involving the bulk of the frontal lobe. While abnormal sulci were apparent in the right parietal region, the temporal and occipital lobes appeared to be spared. She does not have the C502T mutation found in her younger sister.

\section{DISCUSSION}

Of the 22 affected subjects in families 1-11, 13 met our diagnostic criteria for RTT and of the 12 tested seven had a detectable MECP2 mutation, in line with previous reports of mutations in sporadic cases of classical RTT. One affected girl had died and could not be included in the mutation testing.

Nine of the 21 living, affected subjects in these families had some but not all of the criteria for classical RTT. None had a detectable mutation. We had previously found a mutation in only one of five female patients who had some clinical features of RTT but did not fulfil the diagnostic criteria. ${ }^{14}$ The failure to find a mutation in the coding region of the $M E C P 2$ gene, however, especially in a patient with an atypical form of RTT, does not exclude the possibility of a mutation in the $3^{\prime}$ UTR or the promoter region ${ }^{33}$ or a deletion that would not be detected by standard methods of DNA sequencing. It is also possible that the RTT-like phenotype may result from mutations in other genes or it may arise as a phenocopy from environmental damage in pre- or postnatal life. A different gene is especially likely to be involved where affected sisters do not share a maternal Xq28 haplotype, where the mother does not have skewed X inactivation, or where a shared Xq28 haplotype is not of grandpaternal origin.

In this series of 11 possibly familial RTT cases, we found only one family in which the two affected subjects did indeed share the same MECP2 mutation (I.4 and I.5). Their mother also had this mutation detected in her peripheral blood leucocytes but did not have RTT. X inactivation studies showed that there was extreme skewing in her leucocytes, whereas her affected daughters had random $\mathrm{X}$ inactivation. Although healthy carrier mothers have been reported previously, this remains a rare occurrence. Of the remaining 10 families with two subjects with a history of major developmental difficulties compatible with the occurrence of MeCP2 pathology, a MECP2 gene mutation was found in only one affected member in five families, and no MECP2 mutation was found in either affected member in the other five families. It is likely, therefore, that when a probable case of RTT already exists in a family, this may influence the clinician when reaching a diagnosis in a second developmentally delayed members of the same family. Our data suggest that other underlying causes for a developmental disturbance should be sought in these subjects. Recurrence of RTT in a family would appear to be rare and it is important to seek other underlying causes for developmental delay in the sibs and other relatives of true RTT cases. With the identification of causative mutations for RTT in the MECP2 gene, it is now possible to offer carrier testing to female family members. Familial cases are rare and, given the very low risks of recurrence for RTT, gonadal mosaicism must be rarer still. The demand for carrier testing in the female relatives of affected girls, however, is likely to increase. Families in whom a mutation has been identified in the affected girl, and where the mother is shown not to carry the mutation, may still request testing for healthy sisters, because of the remote possibility of mosaicism in one (either) parent. Although a high level of reassurance can be offered without testing, it is understandable that families who have lived with this devastating condition would want as much reassurance as is available. We had requests for carrier testing from two sisters of classically affected girls in this series; in one case the mother was shown to be an unaffected carrier of a MECP2 mutation (family 1) and in the other case (family 4) the mother had previously been shown not to carry the relevant gene mutation. These two sisters of affected girls were shown not to be carriers. We have also had several requests to test the healthy sisters of other sporadic cases of RTT with proven $M E C P 2$ mutations; all have been found not to carry the relevant mutation. It is uncertain how many mutation negative mothers of mutation positive girls with RTT will request prenatal testing in future pregnancies, but this may well be requested on a regular basis.

In conclusion, RTT is a relatively common cause of profound developmental delay in females, but the diagnosis relies upon the accepted clinical diagnostic criteria that are strongly predictive for the presence of a MECP2 mutation. Where a mutation has been detected in an affected female, the chance that a sib or other relative with developmental disturbance will be affected by the same mutation is small. Although the recurrence risks for RTT are low, for the offspring of unaffected sisters of both familial and sporadic cases and for the offspring of the mutation negative mothers of mutation positive affected daughters, we appreciate that many relatives will request genetic carrier testing and some may request prenatal diagnosis even where the risk of recurrence is the risk of mosaicism.

\section{ACKNOWLEDGEMENTS}

We would like to thank all the families who have contributed their time and blood towards this project, and all the clinicians involved in recognising the clinical features of the affected girls and referring them on for further assessment. In particular we wish to thank Drs Fengqing Xiang, Tessa Webb, Maria Anvret, and Geoff Woods for assistance in identifying the linkage analysis results of patients previously reported in their published papers.

\section{Authors' affiliations}

H Gill, J P Cheadle, J Maynard, N Fleming, D Ravine, A Clarke, Institute of Medical Genetics, University of Wales College of Medicine, Heath Park, Cardiff CF 14 XXN, UK

$\mathrm{S}$ Whatley, Department of Medical Biochemistry, University Hospital of Wales, Heath Park, Cardiff CF 14 4W, UK

T Cranston, Clinical Molecular Genetics, Level 5, Camelia Botnar Laboratories, Great Ormond Street, London WC IN 3JH, UK

E M Thompson, South Australia Clinical Genetics Service, Women's and Children's Hospital, 72 King William Road, North Adelaide 5006,

South Australia

J Christodoulou, Western Sydney Genetics Programme, Children's Hospital at Westmead and Department of Paediatrics and Child Health, University of Sydney, Sydney, Australia

H Leonard, TVW Telethon Institute for Child Health Research, West Perth, Australia WA6872

M Davis, Department of Neuropathology, Royal Perth Hospital, Perth, Australia

O Skjeldal, Department of Paediatrics, Nordland Central Hospital, N-8017 Bodo, Norway

F Hanefeld, Ábteilung Kinderheilkunde, Scheuerpunk, Neuropaeditre, Georg-August-Universital, Göttingen, Germany

A Kerr, University of Glasgow, Department of Psychological Medicine, Gartnaval Royal Hospital, 1055 Great Western Road, Glasgow G12 $\mathrm{OXH}, \mathrm{UK}$

A Tandy, Department of Paediatrics, Taunton and Somerset Hospital, Musgrove Park, Taunton, Somerset TA 1 5DA, UK

Correspondence to: Professor A Clarke, Department of Medical Genetics, University of Wales College of Medicine, Heath Park, Cardiff CF14 4XN, UK; clarkeaj@cardiff.ac.uk 


\section{REFERENCES}

1 Clarke A, Schanen C, Anvret M. Towards the genetic basis of Rett syndrome. In: Kerr A, Witt-Engerstrom I, eds. Rett disorder and the developing brain. Chapter 2. Oxford and New York: Oxford University Press, 2001:27-55.

2 Thomas GH. High male-female ratio of germ-line mutations: an alternative explanation for postulated gestational lethality in males in X-linked dominant disorders. Am J Hum Genet 1996;58:1364-8.

3 Trappe R, Laccone F, Cobilanschi J, Meins M, Huppke P, Hanefeld F, Engel W. MECP2 mutations in sporadic cases of Rett syndrome are almost exclusively of paternal origin. Am J Hum Genet 2001;68:1093-101.

4 Girard M, Couvert P, Carrie A, Tardieu M, Chelly J, Beldjord C, Bienvenu T. Parental origin of de novo MECP2 mutations in Rett syndrome. Eur J Hum Genet 2001;9:231-6.

5 Rett Syndrome Diagnostic Criteria Working Group. Diagnostic criteria for Rett syndrome. Ann Neurol 1988;23:425-8.

6 Kerr AM, Mitchell JM, Robertson PE. Short fourth toes in Rett syndrome biological indicator. Neuropediatrics 1995;26:72-4

7 Glasson EJ, Bower C, Thomson MR, Fyfe S, Leonard S, Rousham E, Christodoulou J, Ellaway C, Leonard H. Diagnosis of Rett syndrome: can a radiograph help? Dev Med Child Neurol 1998;40:737-42.

8 Hagberg B. Clinical criteria, stages and natural history. In: Hagberg B, Anvret M, Wahlstrom J, eds. Rett syndrome - clinical and biological aspects. Chapter 2. Clinics in Developmental Medicine No 127 Cambridge: MacKeith Press/Cambridge University Press, 1993:4-20.

9 Goutieres F, Aicardi J. Atypical forms of Rett syndrome. Am J Med Genet 1986;24:183-94

10 Skjeldal OH, von Tetzchner S, Jacobsen K, Smith L. Rett syndrome: distribution of phenotypes with special attention to the preserved speech variant. Neuropediatrics 1995;26:87.

11 Zapella M. The Rett girls with preserved speech. Brain Dev 1992;14:998-1001.

12 Geerdink N, Rotteveel JJ, Lammens M, Sistermans EA, Heikens GT, Gabreels FJ, Mullaart RA, Hamel BC. MECP2 mutation in a boy with severe neonatal encephalopathy: clinical, electropathological and molecular findings. Neuropediatrics 2002;33:33-6.

13 Amir RE, van den Veyver IB, Wan M, Tran CQ, Francke U, Zoghbi HY. Rett syndrome is caused by mutations in X-linked MECP2 gene, encoding methyl-CpG-binding protein 2. Nat Genet 1999;23:185-8.

14 Cheadle JP, Gill H, Fleming N, Maynard J, Kerr A, Leonard H, Krawczak M, Cooper DN, Lynch S, Thomas NST, Hughes HE, Hulten M Ravine D, Sampson JR, Clarke AJ. Long-read sequence analysis of the MECP2 gene in Rett syndrome patients: correlation of disease severity with mutation type and location. Hum Mol Genet 2000;9:1 $119-29$.

15 Wan M, Lee SSJ, Zhang X, Houwink-Manville I, Song HR, Amir RE, Budden S, Naidu S, Pereira JLP, Lo IFM, Zoghbi H, Schanen NC, Francke U. Rett syndrome and beyond: recurrent spontaneous and familial MECP2 mutations at CpG hotspots. Am J Hum Genet 1999;65: 1520-9

16 Bienvenu T, Carrie A, de Roux N, Vinet MC, Jonveaux $P$, Couvert $P$, Villard L, Arzimanoglou A, Beldjord C, Fontes M, Tardieu M, Chelly J. MECP2 mutations account for most cases of typical forms of Rett syndrome. Hum Mol Genetics 2000;9:1377-84.
17 Huppke $\mathbf{P}$, Laccone F, Kramer N, Engel W, Hanefeld F. Rett syndrome: analysis of MECP2 and clinical characterization of 31 patients. Hum Mol Genetics 2000;9:1369-75

18 Amir RE, van den Veyver IB, Schultz R, Malicki DM, Tran CQ, Dahle EJ, Philippi A, Timar L, Percy AK, Motil KJ, Lichtarge O, Smith EO'B, Glaze DG, Zoghbi HY. Influence of mutation type and X chromosome inactivation on Rett syndrome phenotypes. Ann Neurol 2000;47:670-9.

19 Amano K, Nomura Y, Segawa M, Yamakawa K. Mutational analysis of the MECP2 gene in Japanese patients with Rett syndrome. Hum Genet 2000;45:231-6.

20 Xiang F, Buervenich S, Nicolao P, Bailey MES, Zhang Z, Anvret M. Mutation screening in Rett syndrome patients. J Med Genet 2000;37:250-5.

21 Obata K, Matsuishi T, Yamashita Y, Fukuda T, Kuwajima K, Horiuchi I, Nagamitsu S, Iwanaga R, Kimura A, Omori I, Endo S, Mori K, Kondo I. Mutation analysis of the methyl-CpG-binding protein 2 gene (MECP2) in patients with Rett syndrome. J Med Genet 2000;37:608-10.

22 Hampson K, Woods CG, Latif F, Webb T. Mutations in the MECP2 gene in a cohort of girls with Rett syndrome. J Med Genet 2000;37:610-12.

23 Schanen NC, Dahle EJR, Capozzoli F, Holm VA, Zoghbi HY, Francke U. A new Rett syndrome family consistent with X-linked inheritance expands the X chromosome exclusion map. Am J Hum Genet 1997;61:634-41.

24 Villard L, Kpebe A, Cardoso C, Chelly J, Tardieu M, Fonts M. Two affected boys in a Rett syndrome family. Neurology 2000;55:1 188-93.

25 Sirianni N, Naidu S, Pereira J, Pillotto RF, Hoffman EP. Rett syndrome: confirmation of X-linked dominant inheritance and localization of the gene to Xq28. Am J Hum Genet 1998;63:1552-8.

26 Allen RC, Zoghbi HY, Moseley AB, Rosenblatt HM, Belmont JW. Methylation of Hpall and $\mathrm{Hphl}$ sites near the polymorphic CAG repeat in the androgen receptor gene correlates with $\mathrm{X}$ chromosome inactivation. Am J Hum Genet 1992;51:1229-39.

27 Clarke A, Gardner-Medwin D, Richardson J, McGann A, Bonham JR, Carpenter KH, Bhattacharya S, Haggerty D, Fleetwood JA, Aynsley-Green A. Abnormalities of carbohydrate metabolism and of OCT gene function in the Rett syndrome. Brain Dev 1990;12:1 19-24.

28 Xiang $F$, Zhang Z, Clarke A, Joseluiz P, Sakkubai N, Sarojini B, Delozier-Blanchet CD, Hansmann I, Edstrom L, Anvret M. Chromosome mapping of Rett syndrome: a likely candidate region on the telomere of Xq. J Med Genet 1998;35:297-300.

29 Webb T, Clarke A, Hanefeld F, Pereira JL, Rosenbloom L, Woods CG. Linkage analysis in Rett syndrome families suggests that there may be a critical region at Xq28. J Med Genet 1998:35:997-1003.

30 Leonard H, Walsh P, Hockey A. Further documentation of familial Rett syndrome. Eur Child Adolesc Psychiatry 1997;6(suppl 1):92A

31 Leonard H, Fyfe S, Dye D, Leonard S. Familial aggregation in Rett syndrome. What is the evidence for clustering of other disorders in the families of affected girls ? Am J Med Genetics 1999:82:228-34.

32 Leonard H, Fyfe S, Dye D, Hockey A, Christodolou J. Family data in Rett syndrome: association with other genetic disorders. J Paediatr Child Health 2000;36:336-9.

33 Coy JF, Sedlacek Z, Bachner D, Delius H, Poustka A. A complex pattern of evolutionary conservation and alternative polyadenylation within the long 3'-untranslated region of the methyl-CpG-binding protein 2 gene (MeCP2) suggests a regulatory role in gene expression. Hum Mol Genet 1999:8: 1253-62 